\title{
Evaluation and Comparison of Skeletal and Dental Components of Deep Overbite Malocclusion with Normal Occlusion
}

\author{
Harshil Naresh Joshi ${ }^{1}$, Santosh Kumar Goje ${ }^{2}$, Jay Soni ${ }^{3}$, Samarth Chellani ${ }^{4}$, Arth Patel ${ }^{5}$, Jay Patel ${ }^{6}$, M. Devyani Bhardwaj $^{7}$ \\ 1,2, 4, 6 Department of Orthodontics \& Dentofacial Orthopaedics, K.M. Shah Dental College \& Hospital, Piparia, Vadodara, \\ Gujarat, India. ${ }^{3,5}$ Department of Orthopaedics, Ahmedabad Dental College \& Hospital, Ahmedabad, India. ${ }^{7}$ Hitkarini \\ Dental College \& Hospital, Jabalpur, Madhya Pradesh, India.
}

\section{ABSTRACT}

\section{BACKGROUND}

A deep overbite may be due to an underlying skeletal or dentoalveolar component that may influence the treatment plan. The purpose of this study was to evaluate and compare the different components of deep bite malocclusion and normal occlusion.

\section{METHODS}

This was a case control study. Lateral cephalograms and study casts of normal $(\mathrm{N}=$ $50)$ and deep overbite $(\mathrm{N}=50)$ subjects were used to evaluate skeletal and dentoalveolar components. Data was analysed statistically by independent $\mathrm{t}$ - test.

\section{RESULTS}

The significant skeletal contributing factors were gonial angles, mandibular plane, maxillary plane angle \& ramus / Frankfort horizontal. An increased curve of Spee and decreased mandibular first molar height were predominant dental variables in the deep overbite group. The inclination of the upper incisors \& lower incisors height did not show a statistically significant difference between the two groups.

\section{CONCLUSIONS}

The counterclockwise rotation of the mandible and the increased curve of Spee were the dominant features of deep bite malocclusion. This analysis of deep overbite components could help clinicians design individualised mechanotherapy based on the underlying cause rather than being prejudiced toward conventional mechanics when correcting with a deep overbite malocclusion.

\section{KEY WORDS}

Skeletal and Dental Components, Deep Overbite, Ramus / Frankfort Horizontal
Corresponding Author: Dr. Harshil Naresh Joshi, Senior Lecturer, Department of Orthodontics and Dentofacial orthopaedics K. M. Shah Dental College and Hospital, SumandeepVidyapeeth, Pipariya, Waghodia, Vadodara, Gujarat - 391760, India. E-mail: drharshiljoshi11@gmail.com

DOI: $10.14260 /$ jemds $/ 2021 / 318$

How to Cite This Article: Joshi HN,Goje SK, Soni J, et al. Evaluation and comparison of skeletal and dental components of deep overbite malocclusion with normal occlusion. J Evolution Med Dent Sci 2021;10(20):1519-1524, DOI: 10.14260/jemds/2021/318

Submission 01-01-2021,

Peer Review 12-03-2021,

Acceptance 19-03-2021,

Published 17-05-2021.

Copyright (C) 2021 Harshil Naresh Joshi et al. This is an open access article distributed under Creative Commons Attribution License [Attribution 4.0 International (CC $B Y 4.0)]$ 


\section{BACKGROUND}

Consideration of facial type plays an important role in the formulation of an orthodontic treatment plan and prognosis of treatment. Of particular importance is the vertical relationship i.e., whether an individual is long - faced or short - faced. The vertical facial type provides a clue regarding the growth direction of the facial complex and should be used with an anteroposterior classification to describe a patient's face. ${ }^{1}$ The vertical development of the facial skeleton has been related to many skeletal units. The naso - maxillary complex, the alveolar processes, and the mandible have all been associated with normal and abnormal vertical development. ${ }^{2}$ A relationship exists between the structures of the anterior part of the maxilla, mandible, and lower facial height such that in cases with an open bite or a deep bite, the vertical dentoalveolar development may be inappropriate to compensate for the large or small distance between the jaws. ${ }^{3}$

Both condylar and sutural growth and alveolar development play crucial roles in the formation of the facial skeleton. Differential growth in these structures is particularly influential in terms of vertical development of facial characteristics. The sensitivity of these structures to mechanical stress or stimuli or both provides a basis for functional or orthognathic treatment. The alveolar structure forms the functional component of jaws and participates in occlusal dynamics through the teeth. Alveolar structure plays a compensatory role in establishing sagittal and vertical maxillomandibular relationships. ${ }^{4}$

During growth, the vertical and sagittal relationship of the jaws may not be always perfect. In cases where imperfections exist, the relationship between the jaw is secured through the eruption and positioning of the teeth along their basal arches. This is referred to as "Dentoalveolar compensatory mechanism". 5

A deep overbite is one of the most common malocclusions in orthodontic practice. The occurrence of traumatic occlusion due to a deep bite is fortunately rare, but when it does happen, the results can be devastating. Severe deep bite (overbite $>5 \mathrm{~mm}$ ) affects about $20 \%$ of children and $13 \%$ of adults, while open bite (negative overbite greater than $2 \mathrm{~mm}$ ) occurred in less than $1 \%$. The severe deep bite was found nearly twice more prevalent in whites than blacks or Hispanics, while open bite greater than $2 \mathrm{~mm}$ is five times more prevalent in blacks than in whites or Hispanics. ${ }^{5}$

Maxillary incisors play an important role as they provide the anterior guiding slope for protrusive excursions of the mandible. The position and axial inclination of the upper and lower incisors is also an important factor in determining facial aesthetics. The position of the upper and lower incisors relative to each other and their supporting bones is an important feature in case analysis, post-treatment stability, harmony and balance of the facial profile.

F Graf von Spee, who used skulls with abraded teeth to define a line of occlusion, first described the curve of Spee in 1890. The functional significance of the curvature has not been completely understood. However, it has been suggested that the curve of Spee has a biomechanical function during food processing by increasing the crush - shear ratio between the posterior teeth and the efficiency of occlusal forces during mastication. Recently, the curve of Spee and / or levelling of this curve has been related to incisor overbite, lower arch circumference, lower incisor proclination and craniofacial morphology. A deep curve of Spee is usually associated with an increased overbite. Orthodontic correction of the overbite often involves levelling the curve of Spee by the anterior intrusion, posterior extrusion, or a combination of these actions. The process of proclining the lower incisor has been used in some cases to decrease the relative vertical overlap of the lower incisors by the upper incisors. Levelling of the curve of Spee represents a routine procedure in orthodontic practice. Clinicians have been concerned for some time with the degree of reduction in arch circumference that accompanies the levelling of the curve of Spee because they believe that this leads to incisor protrusion. ${ }^{6}$

The role of compensation in the development of overbite had been demonstrated in many previous studies. This can involve the height, depth, and volume of the symphysis and anterior part of the maxilla.

Few studies have dealt with the components of skeletal deep bite. It was shown that the vertical component of mandibular growth has a more remarkable effect than the rotational component. ${ }^{6}$ The mandibular skeletal changes were twice as important as the mandibular dental changes and about 2.5 times as important as the maxillary changes in inducing overbite changes. ${ }^{7}$

A new skeletal measurement, RAMUS / Frankfort horizontal, was made between a tangent to the posterior border of the mandibular ramus and the Frankfort horizontal plane. Measuring this angle in the deep bite sample aimed to test whether the direction of growth and the angulations of the mandibular ramus have significant role in developing deep bite malocclusions. Validation of this parameter is required by further investigation. ${ }^{8}$

Previous studies $6,7,8$ evaluated the components of the deep bite. Among these studies, only one study had introduced the new parameter ramus / Frankfort horizontal plane which also contributes significantly to causing deep bite. But they have not compared this angle with those having normal occlusion. The ramus / Frankfort horizontal plane angle in deep bite patients had shown significant results but further measurements of the same angle is needed in a sample with normal occlusion. Therefore, there was a need to evaluate the contributing components of deep bite including the new parameter and compare these values with the control group with normal occlusion.

The study objective was to evaluate the contributing skeletal and dental components of deep bite \& normal occlusion. In this study, we intend to explore the different components of deep bite malocclusion along with normal occlusion and determine their actual contributions in its development with reference to normal occlusion and also to evaluate whether the direction of growth and the angulation of the mandibular ramus have significant role in developing deep bite malocclusions.

\section{METHODS}

The was a case control study conducted from Oct 2015 to March 2016. The sample comprised of pre-treatment lateral cephalograms and study models of participants who were selected from the archives of Department of Orthodontics, K. 
M. Shah Dental College and Hospital, and from students of KMSDCH Piparia, Vadodara.

\begin{tabular}{|c|c|c|}
\hline & Measurement & Definition \\
\hline \multirow{6}{*}{ Dental } & $\begin{array}{c}\text { Maxillary anterior } \\
\text { alveolar and basal } \\
\text { height }(\mathrm{Mx}-\mathrm{AABH}, \mathrm{Mm})\end{array}$ & $\begin{array}{l}\text { Interspace between the midpoint of the } \\
\text { alveolar meatus of the maxillary central } \\
\text { incisor and the intersection point between } \\
\text { the palatal plane and the long axis of the } \\
\text { maxillary central incisor. }\end{array}$ \\
\hline & $\begin{array}{c}\text { Maxillary posterior } \\
\text { alveolar and basal } \\
\text { height }(\mathrm{Mx}-\mathrm{PABH}, \mathrm{Mm})\end{array}$ & $\begin{array}{l}\text { Perpendicular distance between the } \\
\text { midpoint of the alveolar meatus of the } \\
\text { maxillary first molar and the palatal plane. }\end{array}$ \\
\hline & $\begin{array}{l}\text { Inclination of the upper } \\
\text { incisors (U1 / SN) }\end{array}$ & $\begin{array}{l}\text { Angle formed between the extension of the } \\
\text { long axis of the maxillary incisor and the } \\
\text { sella - nasion plane. }\end{array}$ \\
\hline & $\begin{array}{c}\text { Mandibular anterior } \\
\text { alveolar and basal } \\
\text { height (Md - AABH, Mm) }\end{array}$ & $\begin{array}{l}\text { Distance between the midpoint of the } \\
\text { alveolar meatus of the mandibular central } \\
\text { incisor and the intersection point between } \\
\text { the mandibular plane and the long axis of } \\
\text { the mandibular central incisor. }\end{array}$ \\
\hline & $\begin{array}{l}\text { Mandibular posterior } \\
\text { alveolar and basal } \\
\text { height (Md - PABH, } \\
\text { Mm.) }\end{array}$ & $\begin{array}{l}\text { Perpendicular distance between the } \\
\text { midpoint of the alveolar meatus of the } \\
\text { mandibular first molar and the mandibular } \\
\text { plane }\end{array}$ \\
\hline & & $\begin{array}{c}\text { Angle formed between the extension of the } \\
\text { long axis of the mandibular incisor and } \\
\text { mandibular plane }\end{array}$ \\
\hline \multirow{5}{*}{ Skeletal } & $\begin{array}{l}\text { Mandibular plane angle } \\
\left(\text { Mndp - } \mathrm{FH},{ }^{\circ}\right)\end{array}$ & $\begin{array}{l}\text { Angle formed between the mandibular plane } \\
\text { and the Frankfort horizontal plane. }\end{array}$ \\
\hline & $\begin{array}{l}\text { Gonial angle (Ar - Go - } \\
\text { Me, }{ }^{\circ} \text { ) }\end{array}$ & $\begin{array}{l}\text { Angle formed at the gonial area between the } \\
\text { posterior border of the ramus and a corpus } \\
\text { line. }\end{array}$ \\
\hline & $\begin{array}{l}\text { Maxillary plane angle } \\
\left(\mathrm{SN}-\mathrm{Mxp}{ }^{\circ}\right)\end{array}$ & $\begin{array}{l}\text { Angle formed between the maxillary plane } \\
\text { and the sella - nasion plane. }\end{array}$ \\
\hline & Ramus / FH $\left({ }^{\circ}\right)$ & $\begin{array}{l}\text { A new skeletal measurement made between } \\
\text { a tangent to the posterior border of the } \\
\text { mandibular ramus and the Frankfort } \\
\text { horizontal plane. }\end{array}$ \\
\hline & Measurement & Definition \\
\hline \multirow{3}{*}{$\begin{array}{c}\text { Dental cast } \\
\text { measurements }\end{array}$} & $\begin{array}{l}\text { Length of the clinical } \\
\text { crown } \\
\text { of the maxillary central } \\
\text { incisors }\end{array}$ & $\begin{array}{l}\text { Line formed between the midpoint of the } \\
\text { cervical margin of the tooth and the } \\
\text { midpoint of the incisal edge. }\end{array}$ \\
\hline & $\begin{array}{l}\text { Length of the clinical } \\
\text { crown } \\
\text { of the mandibular } \\
\text { central } \\
\text { incisors }\end{array}$ & $\begin{array}{l}\text { Line formed between the midpoint of the } \\
\text { cervical margin of the tooth and the } \\
\text { midpoint of the incisal edge. }\end{array}$ \\
\hline & Curve of Spee & $\begin{array}{l}\text { An angle formed between the maxillary } \\
\text { plane and the sella - nasion plane. Line } \\
\text { formed between the deepest point on the } \\
\text { mandibular buccal segment and a horizontal } \\
\text { line formed between the most over erupted } \\
\text { mandibular incisor and the most over an } \\
\text { erupted molar. }\end{array}$ \\
\hline & pha & nd Dental Cast Measurements \\
\hline
\end{tabular}

The experimental group was aged from 14 to 28 years with the following inclusion criteria of deep overbite more than $5 \mathrm{~mm}$, complete eruption of the second molars and no history of orthodontic treatment. While for the control group, normal overjet, normal overbite, Angle's class 1 molar and canine relation, subjects with missing molars or incisors, orthodontically treated, prosthesis or implants were excluded from the study. Pleasant facial profile criteria were followed. The ethical clearance was obtained prior to the start of study. The participants were selected as per the inclusion and exclusion criteria. The sample size of each group was 50 participants. All participants were informed about the purpose of the study and a signed information and consent form was obtained. A lateral cephalogram and diagnostic impressions of the maxillary \& mandibular arch were made by alginate impression material. The alginate impression was poured by the dental stone $\&$ the model was obtained.

Cephalograms were traced and values for the parameters were measured. Table 1 explains linear dental cephalometric parameters. Randomly selected 20 films were retracted by the same examiner after 2 weeks to determine an error in the measurements. On the model, the parameter was measured using a digital vernier callipers. Randomly selected 20 casts were remeasured by the same examiner after 2 weeks to determine the error in the measurements.

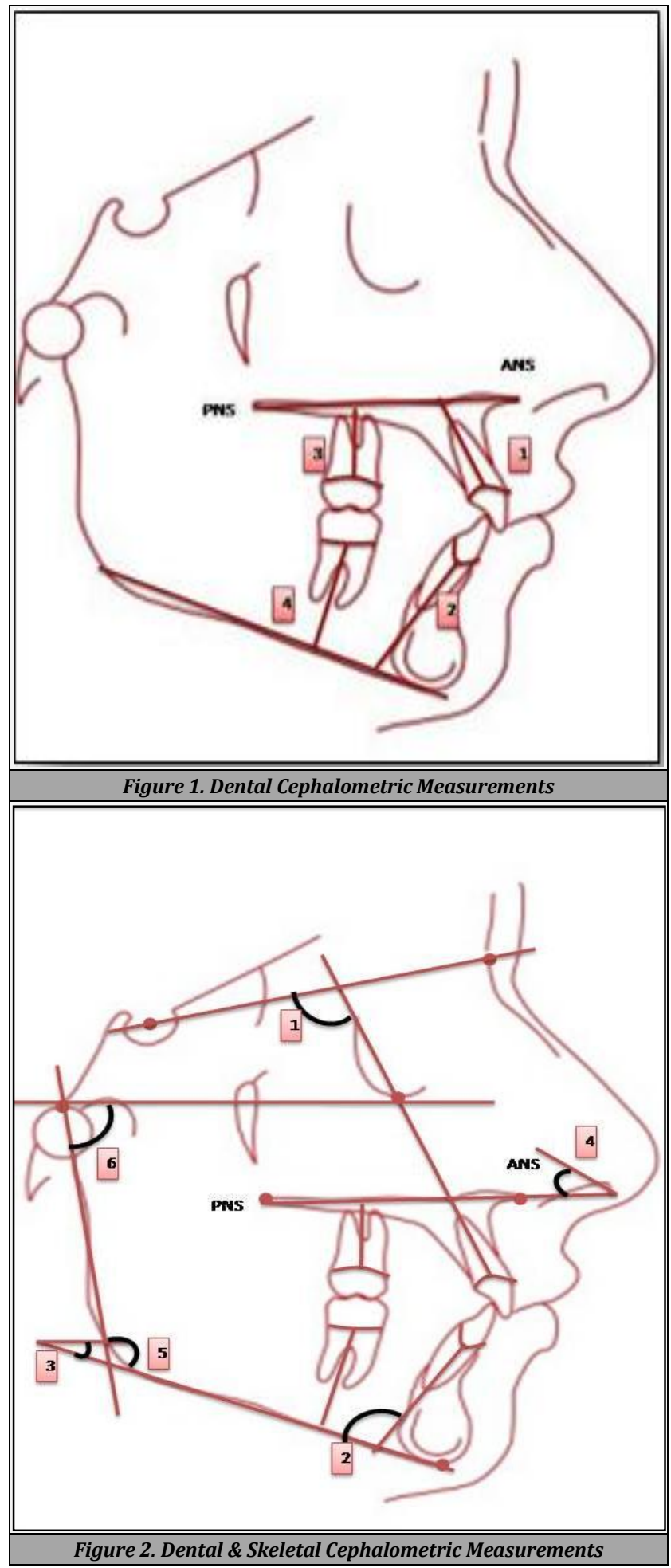

\section{Statistical Analysis}

Descriptive observations were calculated, including the mean and standard deviation \& standard error of the mean for both deep bite malocclusion group \& control group. The percentage of contribution of skeletal \& dental components was also calculated. The Pearson correlation coefficient was 
used to correlate the various deep bite components. The concordance correlation coefficient was used to calculate the intraobserver and interobserver reliabilities.

\section{RESULTS}

\begin{tabular}{|ccccc|}
\hline Control & Mean & SD & SEM & P \\
U1 / sn & 113.06 & 4.8756 & 0.6895 & 0.9165 \\
L1 / mp & 108.78 & 4.845 & 0.685 & 0.0001 \\
U1 Over eruption & 28.8 & 2.610 & 0.3691 & 0.012 \\
L1 Over eruption & 40.28 & 2.695 & 0.38113 & 0.3329 \\
U6 Under eruption & 24.24 & 1.922 & 0.271 & 0.0004 \\
L6 Under eruption & 31.02 & 2.1991 & 0.311 & 0.0001 \\
Mn - Fh plane & 24.78 & 2.6824 & 0.379349 & 0.0013 \\
Sn - mxp & 9.32 & 3.2226 & 0.455 & 0.0010 \\
Gonial angle & 125.82 & 2.50460 & 0.3542 & 0.005 \\
Ramus / Fh & 81.32 & 2.9584 & 0.4183 & 0.0030 \\
U1 Height & 8.35 & 0.9910 & 0.140 & 0.0085 \\
L1 Height & 6.8300 & 0.667 & 0.094 & 0.4296 \\
Curve of Spee & 2.0600 & 0.521 & 0.0737 & 0.0001 \\
\hline Table 2. Control Group (Mean Values of Dental \\
and Skeletal Components in Normal Occlusion) \\
\hline \multicolumn{4}{c}{} \\
\hline
\end{tabular}

\section{Skeletal Components}

The mean value of the mandibular plane angle in control group is $24.7^{\circ}( \pm 2.6) \& 22.2^{\circ}( \pm 4.7)$ in deep over bite group. The difference between these two groups is statistically significant $(\mathrm{P}=0.001)$

- The mean value of the maxillary plane angle in the control group is $9.32^{\circ}( \pm 3.22) \& 7.02^{\circ}( \pm 3.57)$ in deep over bite group. The difference between these two groups is statistically significant $(\mathrm{P}=0.001)$

- The mean value of gonial angle in control group is $125.82^{\circ}( \pm 2.5) \& 123.1^{\circ}( \pm 4.7)$ in deep over bite group. The difference between these two groups is statistically significant $(\mathrm{P}=0.001)$

- The mean value of ramus / Frankfort horizontal plane angle in control group is $81.32^{\circ}( \pm 2.9) \& 78.88^{\circ}( \pm 4.8)$ in deep over bite group. The difference between these two groups is statistically significant $(\mathrm{P}=0.001)$

\section{Dento-Alveolar Components}

- The mean value for inclination of the upper incisors in control group is $113.06^{\circ}( \pm 4.8) \& 113.36^{\circ}( \pm 7.705)$ in deep overbite group. The difference between these two groups is statistical, not significant $(\mathrm{P}=0.816)$

- The mean value for inclination of the lower incisors in control group is $108.78^{\circ}( \pm 4.845) \& 98.7^{\circ}( \pm 6.8)$ in deep overbite group. The difference between these two groups is statistically significant $(\mathrm{P}=0.0001)$

- The mean value for maxillary anterior alveolar and basal height in control group is $28.8( \pm 2.6) \& 30.66( \pm 2.9)$ in deep overbite group. The difference between these two groups is statistically significant $(\mathrm{P}=0.0001)$

- The mean value for mandibular anterior alveolar and basal height in control group is $40.28( \pm 2.6) \& 39.7( \pm$ 3.2) in deep overbite group. The difference between these two groups is statistically significant $(\mathrm{P}=0.0001)$
- The mean value for maxillary posterior alveolar and basal height in control group is $24.24( \pm 1.9) \& 22.86$ ( \pm $1.8)$ in deep overbite group. The difference between these two groups is statistically significant $(P=0.0001)$

- The mean value for mandibular posterior alveolar and basal height in control group is $31.02( \pm 2.1) \& 28.22( \pm$ 2.9) in deep overbite group. The difference between these two groups is statistically significant $(\mathrm{P}=0.0001)$

- The mean value for length of the clinical crown of the maxillary central incisors in control group is $8.35 \pm$ $0.99) \& 8.93( \pm 1.16)$ in deep overbite group. The difference between these two groups is statistically significant $(\mathrm{P}=0.0001)$

- The mean value for length of the clinical crown of the mandibular central incisors in control group is $6.83( \pm$ $0.66) \& 6.94( \pm 0.71)$ in deep overbite group. The difference between these two groups is statistically not significant $(\mathrm{P}=0.4296)$

- The mean value for curve of Spee in control group is 2.06 $( \pm 0.52) \& 2.53( \pm 0.50)$ in deep overbite group. The difference between these two groups is statistically significant $(\mathrm{P}=0.0001)$

\begin{tabular}{|cc|}
\hline $\begin{array}{c}\text { Dentoalveolar Component } \\
\text { (Percentages of Contribution) }\end{array}$ & Deep Bite Group \\
\hline L1 Height & $22 \%$ \\
U1 / SN & $26 \%$ \\
L1 / MP & $31 \%$ \\
U6 Under eruption & $34 \%$ \\
U1 Height & $38 \%$ \\
L1 Over eruption & $46 \%$ \\
L6 Under eruption & $56 \%$ \\
U1 Overeruption & $60 \%$ \\
Curve of Spee & $66 \%$ \\
\hline Table 4. Percentages of Contribution of the Dental \\
Components to a Deep Bite Malocclusion \\
\hline
\end{tabular}

Among the dental components (Table 4), an exaggerated curve of Spee showed the highest contribution to a deep bite malocclusion (66\%), followed by the over eruption of the maxillary incisors $(60 \%)$, the under eruption of the mandibular posterior segment (56\%), the over eruption of the mandibular incisors (46\%), the increased clinical crown length of the maxillary incisors (38\%), the under the eruption of the maxillary posterior segment (34 \%), retroclination of the mandibular incisors (31 \%), the retroclination of the maxillary incisors $(26 \%)$, and the least contributing factor was increased clinical crown length of the mandibular incisors (22\%).

\begin{tabular}{|c|c|c|c|c|}
\hline $\begin{array}{l}\text { Skeletal Component (Percentages } \\
\text { of Contribution) }\end{array}$ & $\begin{array}{l}\text { SN } \\
\text { MXP }\end{array}$ & $\begin{array}{l}\text {-Gonial } \\
\text { Angle }\end{array}$ & $\begin{array}{l}\text { MN - } \\
\text { Plane }\end{array}$ & $\begin{array}{l}\text { FHRamus } \\
\text { / FH }\end{array}$ \\
\hline Deep bite group & $28 \%$ & $42 \%$ & $54 \%$ & $62 \%$ \\
\hline $\begin{array}{r}\text { Table 5. Percentages of } C \\
\text { Components to a } D\end{array}$ & $\begin{array}{l}\text { Contril } \\
\text { eep Bit }\end{array}$ & $\begin{array}{l}\text { bution o } \\
\text { te Maloc }\end{array}$ & $\begin{array}{l}\text { ie Skele } \\
\text { ssion }\end{array}$ & \\
\hline
\end{tabular}

Among the skeletal components (Table.5), The ramus - FH plane angle contributes the most $62 \%$, the mandibular plane angle, counterclockwise rotation of mandible was found to contribute the second most to a deep bite malocclusion (54 $\%$ ), followed by the gonial angle (42\%) and followed by the maxillary plane's clockwise rotation (28\%). 


\section{DISCUSSION}

Many individuals of the normal occlusion group exhibited some skeletal imbalance for one or more of the various anatomical relations which was masked by composite compensation. This effect of composite compensation has been described by Enlow. ${ }^{9,10}$

The mean value of ramus / Frankfort horizontal plane angle in control group was $81.32^{\circ}( \pm 2.9) \& 78.88^{\circ}( \pm 4.8)$ in deep over bite group. The statistical significant difference proved that the / Frankfort horizontal plane angle represents the actual vertical position and angulation of the posterior border of mandibular ramus. It also emphasized the importance of ramal angulations in developing deep bite malocclusions.

Decrease in FH - GoMe angle indicates counter clockwise rotation of the mandible. The horizontal growth pattern plays a key role in the formation of deep bite malocclusion. Similar results were found in the study with Fattahietal. ${ }^{11}$

The gonial angle plays a significant important role in deep over bite group. The analysis of the skeletal components showed the gonial angle was one of the highest shared skeletal factors in deep overbite malocclusion. This clarified the greater contributions of mandibular growth and rotation to the development of skeletal deep over bite compared with maxillary factors.

The influence of the curve of Spee as a contributory factor in causing deep overbite is greatest. As several studies $12,13,14,15$ has reported that the curve of Spee was increased in cases of deep bite. The component with the largest deviation from normal value was the curve of Spee with $66 \%$ as a contributing factor for deep bite malocclusion. Baydas et al. ${ }^{13}$ reported that increasing the curve of Spee leads to an increase in arch circumference and that often leads to extrusion of the lower incisors in direct response.

Such excessive curve of Spee causes muscle imbalance and improper function that can cause lower incisors to overerupt, the premolars \& molars to infra-erupt and the lower molars to be mesially inclined leading to an increase of deep overbite. Excessive vertical overlapping of the anterior teeth may be due to over eruption of the incisor teeth under eruption of the molar and premolar teeth or a combination of both.

The infra eruption of mandibular first molar was statistically different between the two groups in our study. Similar results reported in study done by Modiet al. ${ }^{10}$ and Marques al. ${ }^{9}$ The infra eruption of mandibular first molar was observed in $56 \%$ of the deep bite patients. Profit stated "the insufficient eruption of the posterior teeth can cause upward and forward rotation of the mandible and increase overbite".

A highly significant association of over eruption of maxillary and mandibular incisors and under eruption of maxillary and mandibular posteriors was noted in this study. This was in agreement with Beckmann et al. ${ }^{15}$ who concluded the similar findings in subjects with deep bite. Al-Zubaidi SA and Obaidi HA ${ }^{16}$ also concluded that there was over eruption of mandibular incisors in deep bite cases.

Reduced U1 / SN and L1 / MP angles were found in $26 \%$ and $31 \%$, respectively. The retro inclination of the maxillary incisors and mandibular incisors have a direct effect on the amount of overbite. Subjects with deep bite were showing less low incisor proclination than the normal overbite group. The flaring of lower incisor might be one of the compensations for deep bite.

\section{CONCLUSIONS}

1. Deep bite malocclusion is a complex phenomenon with various skeletal and dento-alveolar components.

2. Ramus / Frankfort horizontal plane angle can be used to identify the skeletal component of deep bite malocclusion provided there is no compensation by body of mandible.

3. A deep curve of Spee was the highest contributing dental factor confirming the importance of intruding the mandibular incisors or extruding the posteriors in deep overbite mechanotherapy.

4. The lingual inclinations of the maxillary and mandibular incisors were among the least shared angular dental components in deep over bite malocclusions. Lower incisor height was the least shared linear dental component in deep bite malocclusion.

Data sharing statement provided by the authors is available with the full text of this article at jemds.com.

Financial or other competing interests: None.

Disclosure forms provided by the authors are available with the full text of this article at jemds.com.

\section{REFERENCES}

[1] McNamara JA Jr. Components of class II malocclusion in children 8-10 years of age. Angle Orthod 1981;51(3):177-02.

[2] Craig CE. The skeletal patterns characteristic of class I and class II, division 1 malocclusions in normalateralis. Angle Orthod 1951;21(4):44-56.

[3] Hitchcock HP. A cephalometric description of class II division 1 malocclusion. Am J Orthod 1973;63(4):41423.

[4] Pancherz H, Zieber K, Hoyer B. Cephalometric characteristics of class II division 1 and class II division 2 malocclusions: a comparative study in children. Angle Orthod 1997;67(2):111-20.

[5] Isik F, Nalbantgil D, Sayinsu K, Arun T. A comparative study of cephalometric and arch width characteristics of class II division 1 and division 2 malocclusions. Eur J Orthod 2006;28(2):179-83.

[6] Baydaş B, Yavuz I, Atasaral N, et al. Investigation of the changes in the positions of upper and lower incisors, overjet, overbite and irregularity index in subjects with different depths of curve of spee.Angle Orthod 2004;74(3):349-55.

[7] Naumann SA, Behrents RG, Buschang PH. Vertical components of overbite change: a mathematical model. Am J OrthodDentofacialOrthop 2000;117(4):486-95.

[8] El-Dawlatly MM, Fayed MMS, Mostafa YA. Deep overbite malocclusion: analysis of the underlying components.Am J OrthodDentofacialOrthop 2012;142(4):473-80.

[9] Marques LS, Armond MC, Ramos-Jorge ML, et al. Correlations between dentoskeletal variables and deep 
bite in class II division 1 individuals.Braz Oral Res 2011;25(1):56-62.

[10] Modi B, Prakash AT, Shetty S, et al.Assessment of dentoalveolar compensation in subject with vertical skeletal dysplasia: a retrospective cephalometric study. J IndOrthod 2013;47(4):255-61.

[11] Fattahi H, Pakshir H, Baghdadabadi NA, et al. Skeletal and dentoalveolar features in patients with deep overbite malocclusion. J Dent (Tehran) 2014;11(6):62938.

[12] Trouten JC, Enlow DH, Rabine M, et al. Morphologic factors in open bite and deep bite. Angle Orthod 1983;53(3):192-211.

[13] Baydas B, Yavuz I, Atasaral N, et al. Investigation of the changes in the positions of upper and lower incisors, overjets, overbite and irregularity index in subjects with different depths of curve of spee. Angle Orthod 2004;74(3):349-55.

[14] Ceylan I, Eroz UB. The effects of overbite on the maxillary and mandibular morphology. Angle Orthod 2001;71(2):110-5.

[15] Beckmann SH, KuitertRB, Prahl-Andersen B, et al. Alveolar and skeletal dimensions associated with overbite. Am J OrthodDentofacialOrthop 1998;113(4):443-52.

[16] Al-Zubaidi SA, Obaidi HAA. The variation of the lower anterior facial height and its component parameters among the three over bite relationships (Cephalometric study). Al-Rafidain Dent J 2006;6(2):106-13. 